\title{
Research on the Innovation and Entrepreneurship Talent Cultivation Mode in the Agricultural University
}

\author{
Hongjun $\mathrm{Gu}^{1, \mathrm{a}}$, Jinghui Wang ${ }^{1, \mathrm{~b}}$, Lixin $\mathrm{Hou}^{1, \mathrm{c}}, \mathrm{He}$ Gong ${ }^{1, \mathrm{~d}}$, Yanlei $\mathrm{Xu}^{1, \mathrm{e}}$ and \\ Shijun $\mathrm{Li}^{1, \mathrm{f}^{*}}$ \\ ${ }^{1}$ Jilin Agricultural University, Changchun 130118, Jilin, China \\ aghj_dennis@163.com, b346056461@qq.com, c16665299@qq.com, \\ d29878671@qq.com, ${ }^{\mathrm{d}} 38884119 @ q q . c o m$, Isj0883@sina.com
}

${ }^{*}$ The Corresponding author

Keywords: Innovation and entrepreneurship; Agricultural university; Talent cultivation mode; Information Technology

Abstract. In the context of the "mass innovation and entrepreneurship", it is a profound significance to cultivate the ability of innovation and entrepreneurship of contemporary university students. Combined with various science and technology foundation projects, a good teaching practice platform should be constructed, innovation team should be formed and teaching staff construction should be valued, thus students' comprehensive quality can be improved to adapt to the fierce competition of the future society.

\section{Introduction}

The cultivation of the innovation and entrepreneurship ability of university students has a profound influence on the development of the future economy [1]. In "energetically promotion of higher education and the suggestion of the self-employment of university students", the Ministry of Education of PRC has clearly pointed out that: developing innovation and entrepreneurship education in university is a scientific development concept for education system to study and practice deeply, a significant strategic move to serve the construction of innovative country, an important way to deepen the higher education reform and cultivate the innovation and entrepreneurship and practice ability of university students and an important measure to implement the employment which is drove by entrepreneurship and promote the full employment of university graduates [2-4].

Nowadays, with the rapid development of market economy, the information industry which takes the electronics, communications, computer and other related majors as a main body develops rapidly in fierce economic technology competition and industrial adjustment and becomes an important strategic industry in our country [5-7]. In the context of innovation and entrepreneurship education of university students, this paper starts with information technology majors, discusses the establishment of competition teaching platform, practice platform, innovation team, teaching staff construction and other aspects and provides the basis for cultivating innovative and entrepreneurial talents.

As shown in Fig. 1, this paper researches the following contents as to the innovation and entrepreneurship talent cultivation mode. The experience has been gained taking Jilin Agricultural University as an example.

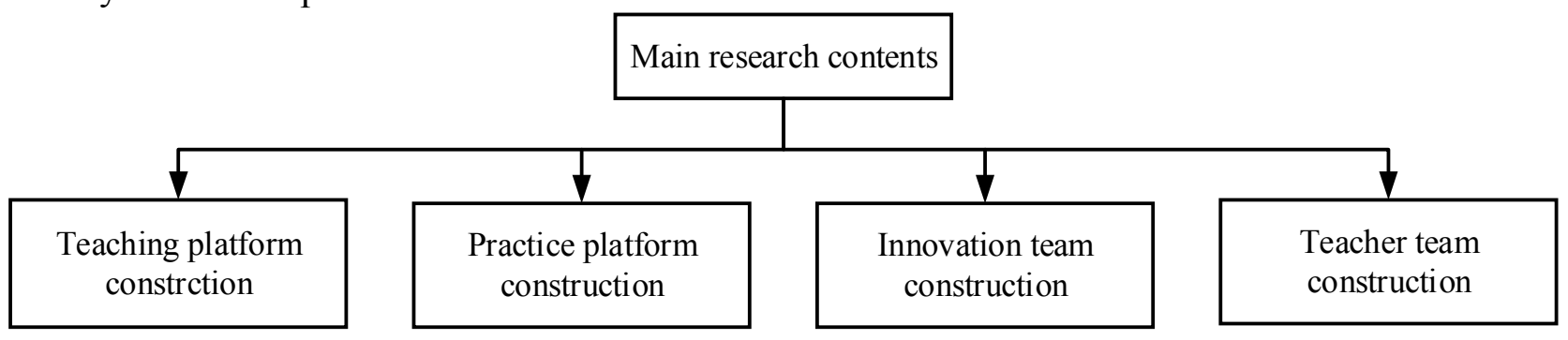

Figure 1. Main research contents 


\section{The Construction of Teaching Platform}

Holding Information Competition Lecture and Stimulating the Innovation and Entrepreneurship Consciousness of Students. The university organizes competition instructors with vice senior and above title to conduct lectures for the competition. The main events are: National/Provincial Electronic Design Competition for University Students, National/Provincial Math Modeling Competition for University Students, The "Challenge Cup" National Extracurricular Academic Science and Technology Competition for University Students(Big Competition), The "Challenge Cup" Extracurricular Academic Papers Competition for University Students (Small Competition), National "Freescale" Cup Smart Car Competition for University Students, National Internet of Things Design Competition for University Students, ACM International Program Design Competition for University Students, China "Internet plus" Innovation and Entrepreneurship Competition for University Students and other school level science and technology events. The content of lectures is about research fund projects that involve university teachers and events. Meanwhile, the lecture also includes developing trends of frontier disciplines.

Science and technology competition lectures can improve students' understanding of various games, cultivate their interest in science and technology and expand their innovative thinking. The object of the lecture includes all teachers of science and engineering and related professional students who are interested in scientific and technological competition. Through the lecture, teachers can communicate with students about the content of the lecture, they will fully understand various scientific and technological competitions, lots of excellent students will be attracted and many innovation teams will be formed.

Paying Attention to Theoretical Study and Laying a Solid Foundation. University basic curriculum education is the cornerstone to cultivate the ability of self innovation and competition practice of university students and the demand of the times for students to adapt to the job department and work environment and do something in their work post [3]. According to the demand of competing practice, targeted courses should be set. The course covers automatic control theory, communication technology, image processing, sensor technology, related algorithms, various microcontrollers and software programming and development. The course integrates the idea of innovation and entrepreneurship, thus the basic knowledge of students can be consolidated.

Enhancing the Practice Teaching Link and the Combination of Theory and Practice of Students. Innovation spirit comes from practice and also the ability of innovation and entrepreneurship comes from practice [8]. The institute of information technology of Jilin agricultural university pays great attention to the practice education link of students and increases inputs year by year. In the aspect of the experiment, comprehensive experiments should be added and the difficulty of them should be increased properly. In the aspect of curriculum design, the topic should have the characteristics of multi-crossed disciplines, wide knowledge, strong function and systematization. In this link, students who have a good foundation and interest should be guided to form a team and prepare for the upcoming competition.

\section{The Construction of Practice Platform}

Our university has set multiple opening innovative labs for innovation and entrepreneurship of university students. They are hardware lab, software lab, algorithm lab, mathematical modeling laboratory and network laboratory and so on. There are specialized teachers who are responsible for these labs. The innovation team can apply for the required computer, electronic components and tools. Meanwhile, in order to meet the demand of scientific research and competition, the university has purchased a $3 \mathrm{D}$ printer. The designed object which is packed is almost the same with the actual products.

During the summer holiday, the university encouraged teachers to lead students to practice in companies and enterprises. By this way, students can exercise their abilities of using hands, meanwhile the vitality of companies can be increased. University also conducted an attempt of 
"school-enterprise cooperation" and received good effects.

\section{The Formation of the Innovation Team}

Innovation team should be formed by students who have the same hobbies and interest. Teachers should give appropriate guidance to them and each team should have talents who have various special talents. When the hardware circuit design and debugging, software programming and debugging, the writing of word documents, the making of PPT, PC interface design, the writing of papers and patents, financial analysis and other issues are involved in various competition, interdisciplinary members should be selected. In the team, each member has their own strengths but they should learn from each other and develop in many ways, thus the team will have the potential to develop.

In the process of participating in a variety of scientific and technological competitions, junior and senior students are the main force, freshmen and sophomores are the fresh force and teachers should give them appropriate guidance. Meanwhile, each team should cultivate their new force to inherit the team spirit. Teachers can play a key role in the team construction and management, they can manage time reasonably, conduct regular communication and discussion, learn while teaching students, help students to improve themselves and provide a good atmosphere for the innovation and entrepreneurship of university students team.

\section{Teaching Staff Construction}

Teachers who can instruct students innovation and entrepreneurship should have innovative spirit and passion, strong practice ability, high academic level and rigorous scholastic attitude. Young teachers are the main force of the teachers at high universities $[9,10]$. The university should encourage young and professional core teachers to take part in domestic academic conferences and improve their occupational ethics and professional practice skills. The university should provide teachers with chances of short-term further education of relevant disciplines, studying abroad as a student or as a visitor and studying for a $\mathrm{PhD}$ so that they can broaden one's horizon and have a growth in knowledge. The university should provide teachers with better teaching and research conditions and encourage them to lead students to companies and the enterprises for a visit. The university should encourage and instruct younger teachers to declare relevant scientific research subjects so that they can have economic security. At the same time, the university will give instructors some reward so that teachers can strengthen their subjective initiative. In the summer and winter vacations, teachers can make full use of the leisure time to do some practical work, which can improve their abilities and the students can make great progress under the direct of the teachers.

\section{Conclusion}

Since 2014, the amount of innovation entrepreneurship competitions that students joined and the amount of teams that declared innovative fund have been both increased through the adjustment of the talent training mode. The number of patents, articles and funds in 2016 is much higher than those in recent years. Meanwhile, there are also national awards leaping from provincial awards. The talents cultivation mode studied in this paper opens a door to success for university students' innovation and entrepreneurship in the future.

\section{Acknowledgements}

The authors wish to express their gratitude to the projects: "12th Five-Year" Education and Science Planning Subjects of Jilin Province (No. GH150208, No. GH150206, and No. ZC13054), and Key Educational Reform Subject of Jilin Agricultural University (No. 2015xjzd27) for their generous support of this work. 


\section{References}

[1] X.J. Zhou, X.Q. Yu and H. Zhu: China Modern Educational Equipment, 2014, No.23, p.63. (In Chinese)

[2] H.J. Gu, H. Gong, and, S,J, Li etc: Industrial and Science Tribune, Vol.14 (2015), No.20, p.159. (In Chinese)

[3] P.He, M. Yin and S.Yu: Heilongjiang education, 2013, No.2, p.54. (In Chinese)

[4] P. Xu, X.T. Liu, Q.Q. Hou, etc: China Electric Power Education, 2013, No.20, p.27. (In Chinese)

[5]B.Z.Shi, J.R.Yuan and Y.M. Zhang: Journal of Heilongjiang College of Education, Vol.32 (2013), No.10, p.5. (In Chinese)

[6] X.Y. Li: MeiTan Higher Education, Vol.30 (2012), No.2,p.23. (In Chinese)

[7] H.J.Gu, S,J, Li and L.X. Hou, etc: Journal of Jilin Agricultural Science and Technology University, Vol.25 (2012), No.2, p.23. (In Chinese)

[8] L.X.Hou, S,J,Li and H.J. Gu, etc: Industrial and Science Tribune, Vol.15 (2016), No.15, p.161. (In Chinese)

[9] S,J,Li, H. Gong, and H.J. Gu, etc: Journal of Jilin Agricultural Science and Technology University, Vol.21 (2012), No.2, p.116. (In Chinese)

[10] H.J.Gu, S,J, Li and L.X. Hou, etc: Industrial and Science Tribune, Vol.15 (2016), No.18, p.213. (In Chinese) 